\title{
The Sustainable City and the Smart City: measuring urban entropy first
}

\author{
R. Fistola ${ }^{1} \&$ R. A. La Rocca ${ }^{2}$ \\ ${ }^{I}$ Department of Engineering, University of Sannio, Italy \\ ${ }^{2}$ Department of Civil, Architectural and Environmental Engineering, \\ University of Naples Federico II, Italy
}

\begin{abstract}
It is quite difficult to define what the Smart City is: some studies try to understand urban smartness by considering a set of variables inside the urban system. Most likely, a different method can be found, starting from the assumption that the city could be considered as a complex system. In a way, we can say that the Smart City is a physical space in which technology is widespread, available and inclusive and supports a new growth of social capital, the renewal of the material urban dimension and allows the development of new functional systems throughout the "virtualization" of some urban activities. The process towards the knowledge of "urban smartness" is conditioned to a first step, which is a common phase in the two new dimensions of modern urban planning: sustainable planning and smart planning. Both of these two dimensions try to manage the evolution of the urban system and drive it towards a future state that should be compatible with the available resources as well as sustainable considering the future needs of human beings as well as the planet. In order to initiate the management of territorial transformation, there is one first obligatory step in common with all new urban planning: the reduction of urban entropy. Urban entropy represents the main obstacle to starting new sustainable processes of urban planning and corresponds to all the kinds of urban dyscrasia that can occur within the urban subsystems. In order to reduce urban entropy, we first need to develop a way to identify and to measure it inside the different city sub-systems. This paper proposes a useful method which can be used to measure it and to envisage urban actions aimed at reducing negativity of the city by using new technologies.
\end{abstract}

Keywords: urban entropy, Sustainable City, systemic approach, entropy variables. 


\section{About urban entropy}

As highlighted by some seminal studies (Mc Loughlin [1]), the systemic approach allows one ('allow' requires an object) to consider the city as a dynamic complex system where complexity is the strategic factor able to ensure system evolution. According to system properties, a subdivision within subsystems is possible. Subsystems, in turn, can be primary or can be related to some specific characteristics (economic, transport, etc.). Referring to these concepts, it is possible to define five main urban subsystems (Fistola and La Rocca [2]):

- The physical subsystem (material type; it is formed by spaces interconnected by channels);

- The functional subsystem (abstract type; it is represented by urban activities);

- The psycho-perceptive subsystem (abstract type; it is represented by the image of the city elaborated by citizens or city users);

- The geomorphologic system (material type; it is formed by environmental factors);

- The anthropic system (abstract type, it is represented by the "biocenotic" component of the city, the community that gives a sense to the space).

Each subsystem has static and dynamic components (table 1) and it is closely related to others as part of the whole system.

Table 1: Static and dynamic dimensions of subsystems.

\begin{tabular}{|l|l|l|}
\hline \multicolumn{1}{|c|}{ SUBSYSTEM } & \multicolumn{1}{|c|}{ STATIC COMPONENT } & \multicolumn{1}{|c|}{ DYNAMICS COMPONENT } \\
\hline PHYSICAL & Adapted spaces & $\begin{array}{l}\text { Physical channels of } \\
\text { communication } \\
\text { (streets, networks, mains, etc.) }\end{array}$ \\
\hline FUNCTIONAL & Urban activities & Communications \\
\hline PSYCO-PERCEPTIVE & Images & $\begin{array}{l}\text { Interpretations } \\
\text { Connections (physical networks } \\
\text { of interconnection) }\end{array}$ \\
\hline GEOMORPHOLOGIC & Territorial areas & Interactions \\
\hline ANTHROPIC & Players & \\
\hline
\end{tabular}

When the parts and relationships of subsystems are properly balanced, cities are in a sustainable dynamic state. Problems arise when one or more subsystems change their normal evolution trajectories and start a considerable production of entropy. An urban crisis depends on the entropy produced inside the city and it needs to be reduced in order to start appropriate processes aimed at urban sustainability.

The peculiarities of urban entropy have already been discussed during the last editions of the Sustainable City Conference. The aim of this study is to get a definition of urban entropy (Fistola [3]) which can be framed into the stream of scientific research concerning the interpretation of the city as a system (thermodynamic). Prigogine and Stengers' studies [4] and the more recent studies developed in Italy (Pulselli and Tiezzi [5]) can represent the main references of indepth analysis regarding the concept of urban entropy.

What we propose here consists in the attempt to measure entropy levels generated within the process of the evolution of urban systems in order to develop urban actions and/or policies able to counteract the entropy effects in advance. 
Recent studies (Aoki [6]) also show that measuring the change in entropy within a complex system could represent a useful tool to manage it. The systemic paradigm, as theoretical reference for this study, allows one to approach the complexity of urban systems but calls for the need to define adequate actions to keep the system within the thresholds of the zone of entropy (fig. 1) during its evolution in time and space. In a possible in-depth development of this study, it would be very interesting to investigate what happens when the system overcomes the thresholds of entropy zones. This is close to Kaufmann's hypothesis: “complex adaptive systems (CAS) evolve to the edge of chaos" [7]. Urban system could be interpreted as CAS because of its capacity to self-regulate according to external stresses; but what happens beyond the chaos limits?

This study cannot answer this question directly, but it attempts to focus on entropy study as a precondition to define actions and policies able to manage urban systems.

\section{Urban evolution, entropy and deterministic chaos}

The assumption of this study refers to the consideration that cities, affected by high levels of entropy, cannot produce an appropriate potential of urban smartness nor support sustainable processes of urban planning.

Entropy has to be considered as a widespread negative condition that hinders the processes required to achieve sustainability and tends to move the urban system towards the "entropy zones" (fig. 1) taking trajectories very different from those expected. This phenomenon has negative influences on the management process of urban systems. Entropy is related to several negative conditions (urban pollution, energy waste, excessive production of urban waste, increment of vulnerability, high social conflicts, high crime rate, etc.) that may produce adverse effects and different kinds of discrepancies within the urban system, related to the improper use of available resources. When the city (urban system) enters entropy zones, it drops out of evolution processes - where entropy can be regulated - and it is necessary to resort to many more resources (economic, social, environmental, etc.) to get the city (urban system) into functional entropy zones. Thus, the mitigation of entropy has to be the main purpose for territorial government. The more we are able to control urban entropy (which the system inevitably generates for its survival and evolution), the more urban development will follow trajectories towards positive states (i.e. sustainable and compatible with the available resources).

Figure 1 shows that entropic zones can be further distinguished into two different ranges:

- recoverable entropy areas,

- unrecoverable entropy areas.

In the first case, it is possible to recover the city (urban system) tracing it back to the range of urban sustainability (although a considerable amount of social, environmental and economic resources are needed). In the second case, the urban system drives itself towards a condition of "heat death" where it suffers structural collapse and the disintegration of the relations among elements. 

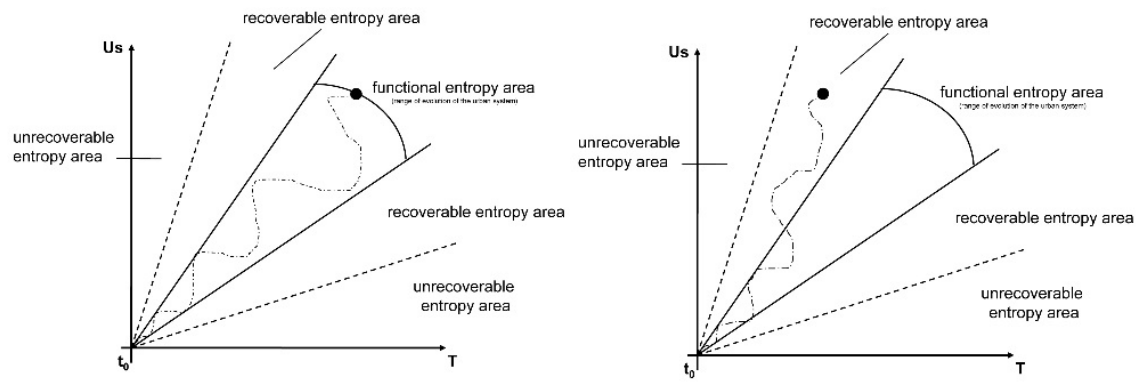

Figure 1: The entropic trend of the urban system in a normal evolution (left) and in the first stage of decay in the recoverable entropy area (right).

In order to give some examples, we can suppose that cities (urban systems) where entropy has been mainly produced by a "dominant" cause (such as urban pollution, strong social conflicts, widespread urban hazard due to natural causes, hydrogeological instability, and so on) are located in recoverable entropy areas. While cities exposed to a constant and very high entropic pressure or hit by disasters (that require evacuation) are located in the state of "heat death" (the case of Chernobyl could be a striking example) and it is impossible to retrieve the relations among subsystems. To describe these phenomena from a more detailed point of view, it is possible to consider a specification of the entropic trend scheme.

Figure 2 shows the evolution of urban system that we can envisage as generated by "local motions" which occur within it. These local motions constantly modify themselves in a dynamic way. Entropy produced by this evolution process cannot be considered dangerous for the system. In this case, entropy is tolerated by the system as necessary for its evolution, even though some chaotic states occur. The "evolution entropy", thus, represents a condition that the system needs in order to evolve and that the system is able to absorb.

This condition connects the concept of "deterministic chaos" for non-linear systems (Fistola [8]). When entropy exceeds the boundary of the evolution area, the system risks passing into the unrecoverable entropy area. This is the state of the "thermic death" where subsystems which make up the city lose their relations definitively or the loss of auto-organization occurs, as Albeverio's studies demonstrate (Albeverio et al. [9]). Auto-organization is based on the existence of a relationship between the subsystems of the city. As mentioned before, the decay into the unrecoverable entropy area can occur in two cases: when the system is not able to tolerate entropy generated by its evolution, or when the levels of entropy increase due to external events. Defining the threshold value of the "entropic decay" represents a basic condition to spare the city from entering into an irreversible state. In this sense, entropy is the main antagonist of urban sustainability; but is it possible to "measure" this phenomenon? This is the main question this study tries to answer. 

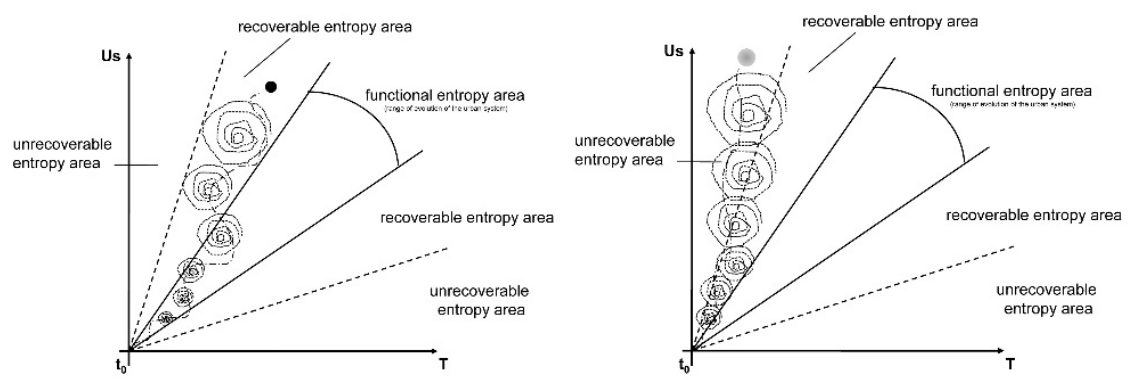

Figure 2: The evolution of the urban system due to local motions. The decay of the urban system into the entropy area (left) and into the unrecoverable entropy area (right) when the heat death of the urban system happens.

As well as urban "smartness" or "sustainability", it is very difficult to define entropy through apposite indicators describing the state of urban systems. This occurrence and the knowledge that entropy can be considered as the opposite of sustainability allows one to approach the problem from a different point of view.

This choice can really appear as a coercing solution, as we know that entropy, as well as sustainability, are complex phenomena that cannot be easily reduced to a simple reverse relation. Nevertheless, we felt that the revisiting of some international sustainability indicators could be the possible starting point in order to achieve the final target of this study: to assess urban entropy.

\section{Urban Sustainability Indicators: criteria and characteristics}

The concept of entropy is very useful to describe the structure and behavior of different systems. It is useful to measure the level of organization versus chaos, uniformity versus diversity, useful versus useless, or order versus disorder in different systems and in different scientific domains (Cabral et al. 2013 [10]). If so, entropy, intended as a condition of crisis of urban livability, can be useful to measure the level of unsustainability (i.e. entropy state) versus sustainability. Starting from this consideration, this part of the study examines some reviews of sustainability indices and indicators with the aim of individuating useful parameters for measuring urban entropy. The thesis this study tries to support will need more in-depth analysis that will be developed in successive phases. At the moment, it speculates on the possibility of defining indicators of urban entropy acting at the opposite: in this sense, sustainability corresponds to a positive state and it is evaluated by "positive indicators" while entropy can be measured by parameters describing negative states or having negative impacts on urban systems. Since its definition in the Brundtland Report (Our Common Future) in 1987 , the production of sustainable indicators has been substantial both by public 
institutions and by academic exponents. This production also comes from the vagueness of the concept of sustainability - widely discussed in literature - and the consequent need to give it an applicative dimension where the urban one has been predominant.

The definition of urban sustainable indicators mainly refers to four dimensions: environmental, economic, social, governmental. Some studies also introduce a fifth dimension referring to the sustainability of the built-up environment intended as the aptitude of the city to improve the liveability of buildings and urban infrastructures without damaging the urban region environment and supporting the local economy.

Among such dimensions, a social component is considered indispensable to measure urban sustainability. Indeed, the metrics used for the measurement of sustainability are various. The ones that are most commonly used refer to Sustainability Reporting, Triple Bottom Line accounting, the Environmental Sustainability Index and the Environmental Performance Index. A more recent approach is represented by Circles of Sustainability proposed by the United Nations Global Compact International Programme as an alternative and critical approach to the Triple Bottom Line. It mainly refers to social aspects of urban life and proposes the measurement of sustainability by a holistic vision across an integrated series of domains (economics, ecology, politics, and culture) (Magee et al. 2012 [11]).

The concept that the "improvement in the quality of life for all segments of population" (Polése and Stren [12]) reminds one of the original principle of the intergenerational equity as a basic condition for sustainable development.

The triple bottom line approach is the main reference in the assessment of sustainability applied to the city (Pope et al. [13]) mostly referring to environmental, social and economic aspects. But as shown by some recent studies (Mori and Christodoulou [14]; Finco and Nijkamp [15]) the concept of urban sustainability remains ambiguous, even though very popular, and almost superseded by the new emergent paradigm of the smart city.

The literature reviews on urban sustainability indicators show that it is very difficult to define sustainability precisely and it is much more complex to reach a unified definition for sustainability applied to the city. This is also due to the increasing difficulty of defining the boundaries of present cities; in fact, administrative boundaries of an urban agglomeration could probably not be the right reference for comparing cities' sustainability level. Mori and Christodoulou [14] report on these difficulties and emphasize the need to define a new City Sustainability Index (CSI) in order to evaluate urban sustainability.

The authors consider different indices (table 2) in order to understand the global impact of cities on human life. Indicators have been classified also referring to the weak/strong sustainability theory (table 3 ). 
Table 2: $\quad$ The most known sustainability indices/indicators. (Source: Mori and Christodoulou [14].)

\begin{tabular}{|c|c|}
\hline INDICES/INDICATORS & DEFINITION \\
\hline Ecological Footprint (EF) & $\begin{array}{l}\text { measures the total consumption of goods and services } \\
\text { produced and the amount of waste assimilated by the global } \\
\text { hectare of bioproductive lands }\end{array}$ \\
\hline Dashboard of Sustainability (DS) & $\begin{array}{l}\text { is a tool for considering the economic, social, and } \\
\text { environmental conditions of development and incorporating } \\
\text { ad hoc set indicators in order to evaluate sustainability }\end{array}$ \\
\hline $\begin{array}{l}\text { Environmental Sustainability } \\
\text { Index (ESI) }\end{array}$ & $\begin{array}{l}\text { assesses individual country's sustainability based on } 5 \text { major } \\
\text { components such as environmental systems, reducing } \\
\text { environmental stresses, reducing human vulnerability, } \\
\text { social and institutional capacity and global stewardship The } \\
\text { five components are composed of } 21 \text { indicators which are } \\
\text { decomposed into } 76 \text { variables }\end{array}$ \\
\hline Welfare Index (WF) & $\begin{array}{l}\text { is the total volume of freshwater that is used to produce the } \\
\text { goods and services consumed by the individual or } \\
\text { community }\end{array}$ \\
\hline Well-Being Index (WI) & $\begin{array}{l}\text { is derived from the mean of a Human Well-being Index } \\
\text { (HWI) and an Ecosystem Well-Being Index (EWI). The } \\
\text { first considers indices of health and population, welfare, } \\
\text { knowledge, culture and society, and equity ( } 36 \text { indicators). } \\
\text { The second comprises indices for land, water, air, species } \\
\text { and genes, and resources deployment ( } 51 \text { indicators) }\end{array}$ \\
\hline $\begin{array}{l}\text { - Genuine Progress Indicator } \\
\text { (GPI) } \\
\text { - Index of Sustainable Economic } \\
\text { Welfare (ISEW) } \\
\text { - Sustainable Net Benefit Index } \\
\text { (SNBI) }\end{array}$ & alternative to the GDP, refer to economic welfare \\
\hline City Development Index & $\begin{array}{l}\text { is a single measure of the level } \\
\text { of development in cities, which is calculated by five sub- } \\
\text { indices such as city product, infrastructure, waste, health } \\
\text { and education }\end{array}$ \\
\hline Energy/Exergy & $\begin{array}{l}\text { tries to value the economy on the same basis as the work of } \\
\text { the environment by the unit of energies }\end{array}$ \\
\hline $\begin{array}{l}\text { Human Development Index } \\
\text { (HDI) }\end{array}$ & $\begin{array}{l}\text { measures the average achievements in a country in three } \\
\text { basic dimensions: life expectancy at birth; adult literacy } \\
\text { rate with gross enrolment ratio in education; and GDP per } \\
\text { capita in purchasing power parity (PPP) US dollars }\end{array}$ \\
\hline $\begin{array}{l}\text { Environmental Vulnerability } \\
\text { Index (EVI) }\end{array}$ & $\begin{array}{l}\text { assesses the vulnerability of physical environment in the } \\
\text { unit of country }\end{array}$ \\
\hline $\begin{array}{l}\text { Environmental Policy Index } \\
\text { (EPI) }\end{array}$ & $\begin{array}{l}\text { is mainly composed of indicators on environmental health } \\
\text { and environmental vitality }\end{array}$ \\
\hline Living Planet Index (LPI) & $\begin{array}{l}\text { assesses the impacts of human activities on ecosystems in } \\
\text { themselves or/and ecosystem functions, referring to } \\
\text { indicators of biodiversity }\end{array}$ \\
\hline Genuine Saving (GS) & Is a measure of the environmental degradation \\
\hline
\end{tabular}


The definition of urban sustainability indicators has often been the object of research especially of those ones aimed at evaluating the effects of urban policies. Shen et al. [16] for example propose an International Urban Sustainability Indicators List (IUSIL). As mentioned above there are many examples in literature aimed at testing the level of urban sustainability by using indicators able to describe the urban context. Whilst there is much attention paid to the definition of urban sustainability, there are very few examples aimed at defining urban indicators to measure entropy and getting conditions to drive the urban system towards sustainability states. This study proposes to shift the attention of the scientific community and suggests possible ways of measuring urban entropy using system paradigm as theoretical support.

\section{Urban sub-systems and entropy indicators}

Entropy describes a general negative state of the urban system and is related to the concept of dissipation and wastefulness of energy. Entropy must be kept between the minimum value - below which the system becomes vulnerable and unstable and the maximum value, above which the system becomes unsustainable. The parameterization of these values is not easy but would be very useful in order to manage the functioning of urban systems. This part of the study aims at defining a possible systematization of indicators able to describe, but also to "parameterize" entropy levels for each of the five subsystems defined before. Table 3 contains the proposed articulation. Entropy indicators have been individualized by considering opposite conditions of sustainable indicators.

Table 3: The proposal for the systematization of entropy indicators.

\begin{tabular}{lll}
\hline SUBSYSTEM & \multicolumn{1}{c}{ DESCRIPTION } & \multicolumn{1}{c}{ INDICATORS/VARIABLES } \\
\hline & & Air quality \\
& & Noise pollution \\
& Indicators refer to & Electromagnetic pollution \\
& conditions that can have & Power consumption per household \\
impacts on liveability & Water consumption per household \\
ANTHROPIC & Quality of car fleet \\
& (healthy, social, & Unemployment rate \\
& environmental) of the & Multi-ethnic composition of residential \\
& system & population \\
& & Number of voluntary associations per 1000 \\
& & inhabitants \\
\hline \multirow{3}{*}{ FUNCTIONAL } & Population density \\
& & Presence of metropolitan functions \\
& & Tertiary activities ratio/commercial activities \\
& Indicators refer to & Supply of multimedia services \\
& activitiem & Urban activities slot \\
& & Urban green spaces and parks \\
& & Sport and recreational structures \\
& & Crowding index \\
& & Waste production \\
\hline
\end{tabular}


Table 3: Continued.

\begin{tabular}{|c|c|c|}
\hline SUBSYSTEM & DESCRIPTION & INDICATORS/VARIABLES \\
\hline PHYSICAL & $\begin{array}{l}\text { Indicators refer to negative } \\
\text { condition of built } \\
\text { environment }\end{array}$ & $\begin{array}{l}\text { Status of the housing stock } \\
\text { Energy-efficient buildings } \\
\text { Status of the school buildings } \\
\text { Disused buildings } \\
\text { Roads conditions } \\
\text { Public transport lanes } \\
\text { Soft mobility paths }\end{array}$ \\
\hline $\begin{array}{l}\text { GEOMORPH- } \\
\text { OLOGICAL }\end{array}$ & $\begin{array}{l}\text { Indictors refer to the level } \\
\text { of natural and anthropic } \\
\text { risk }\end{array}$ & $\begin{array}{l}\text { Flooding risk } \\
\text { Seismic risk } \\
\text { Hydrogeological risk } \\
\text { Territorial utilization rate } \\
\text { Quarries } \\
\text { Fire risk } \\
\text { Landfills } \\
\text { Brownfield } \\
\end{array}$ \\
\hline $\begin{array}{c}\text { PSYCO- } \\
\text { PERCEPTIVE }\end{array}$ & $\begin{array}{l}\text { Indicators refer to } \\
\text { elements which have } \\
\text { impacts on the image of } \\
\text { the city }\end{array}$ & $\begin{array}{l}\text { Building obsolescence } \\
\text { Urban Status } \\
\text { Building quality } \\
\text { Urban Landmark } \\
\text { Building Heritage } \\
\text { Urban lighting } \\
\text { Climate } \\
\text { Unlawful buildings } \\
\text { Civic pride }\end{array}$ \\
\hline
\end{tabular}

\section{Measuring urban entropy: the case study of Benevento}

In this section, we take, as a case study, the city of Benevento in Campania. Benevento is a small sized city (about 60,000 inhabitants) situated in a regional historical zone (Sannio), as its prestigious archeological and historic-artistic heritage demonstrates. The test has been applied to the ancient part of the city, subdivided into 59 census tracts and 572 buildings.

Thematic maps and analyses were carried out by using GIS technology. The final database is a $59 \times 35$ matrix of value referred to five subsystems as shown in Table 3.

Levels of high entropy for the anthropic subsystem (fig. 3) are especially due to air and noise pollution. Actions to reduce these values could refer to mobility policies for example. Reducing car use could probably have positive effects on air and noise pollution levels. Electromagnetic pollution could be reduced by implementing building efficiency and lifestyle of customers and users of public buildings. 


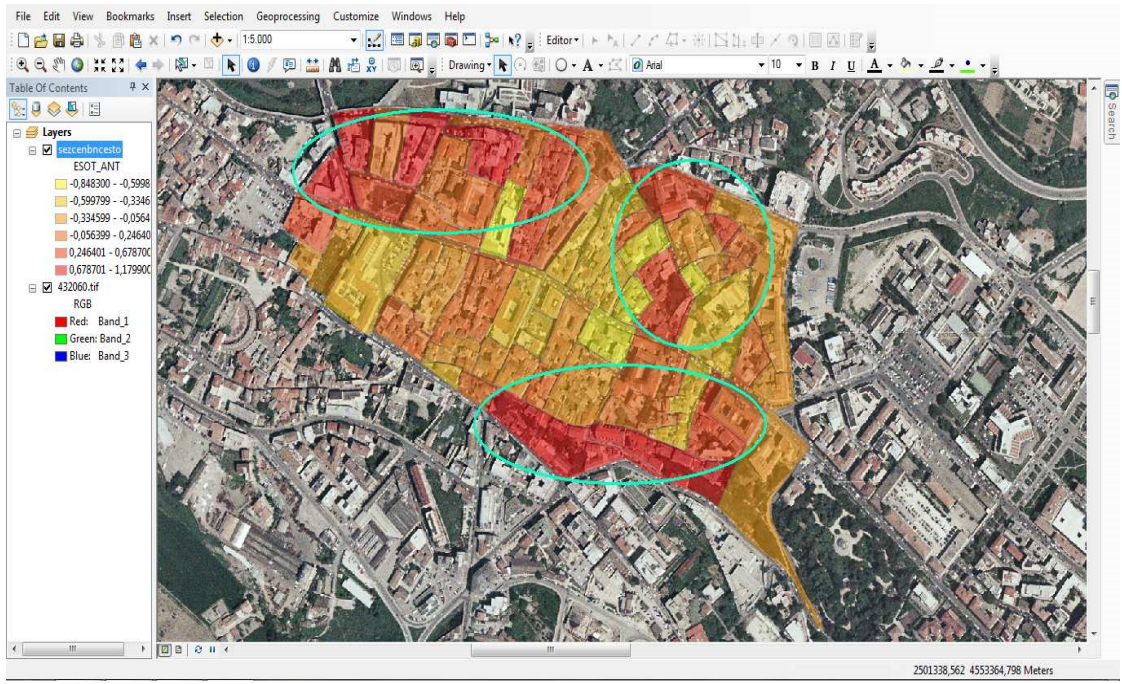

Figure 3: The measure of urban entropy for the Anthropic Subsystem. The red areas correspond to the highest value due to noise and electromagnetic pollution and the unemployment rate.

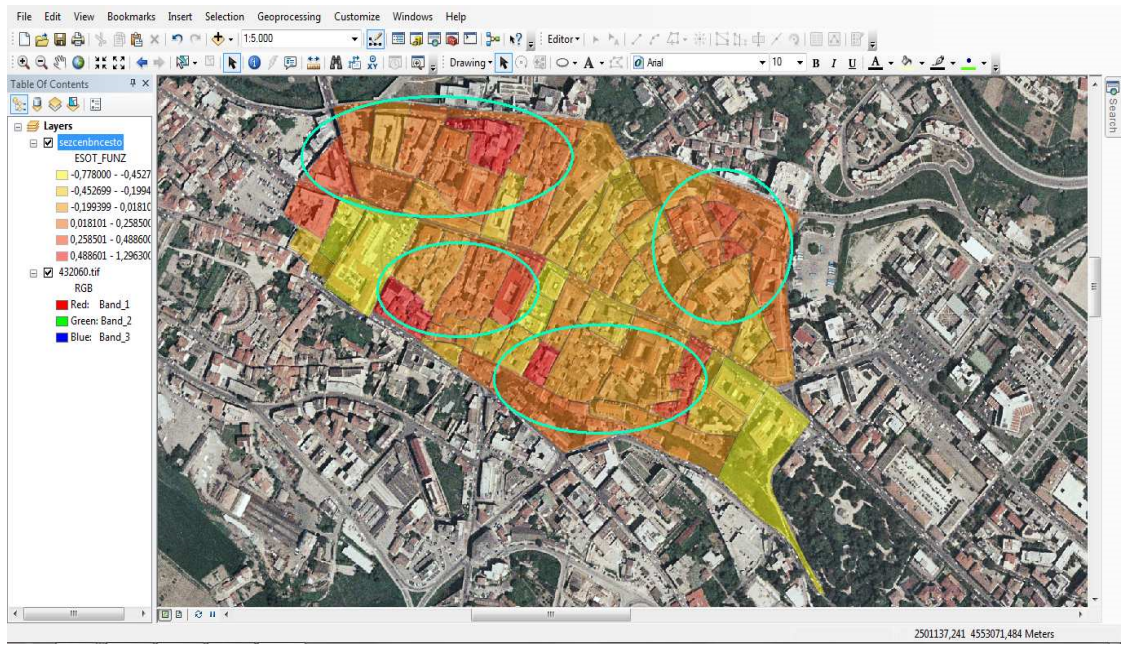

Figure 4: The measure of urban entropy for the Functional Subsystem.

Levels of high "functional entropy" are mainly due to the lack of green urban open spaces and urban parks together with elevated population density value.

The high value of the crowding index characterize this area. Actions should be oriented to the lowering of these negative values, but difficulties are inevitable due to the urban form of this part of the city, also characterized by a lack of urban public services and open spaces. 


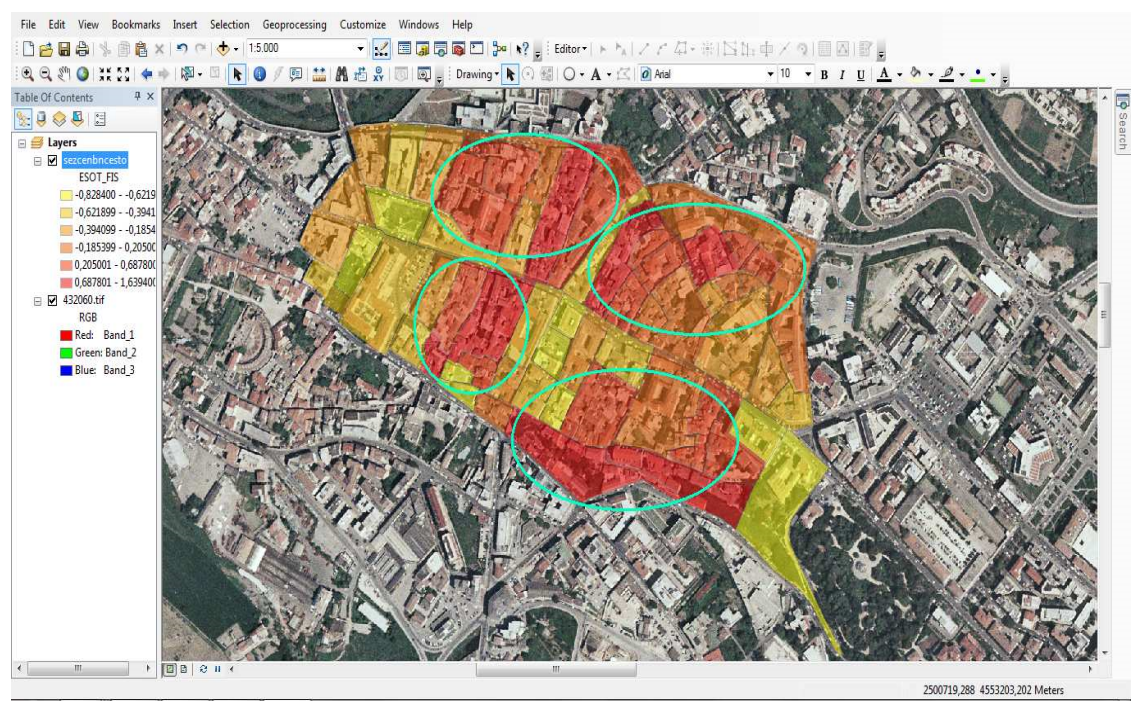

Figure 5: The measure of urban entropy for the Physical Subsystem.

Physical entropy values are due to the obsolescence and the presence of disused buildings (red areas in fig. 5). In these zones the value of building energy efficiency is close to minimum.

\section{Conclusions}

This paper has tried to take the first step towards measuring the urban entropy produced by an urban system during its evolution. The systemic approach to the study of the city allows us to consider the entropy generated inside the different subsystems. This represents a useful method in order to understand how much the total amount of entropy of the urban system is as a whole. Using the GIS it is also possible to visualize the urban places where urban entropy rises to dangerous levels and this could be particularly useful in order to develop urban strategies to mitigate it. The measurement of urban entropy could help to understand how the urban system is able to achieve urban smartness. This is a field of research currently being explored by a number of urban and regional scientists around the world, although it should be noted that the first studies regarding urban entropy were developed within the WIT group of researchers.

\section{References}

[1] Mc Loughlin J. B., Urban and Regional Planning. A Systems Approach, Faber and Faber, London, 1969.

[2] Fistola R. and La Rocca R.A. (2013), "Smart City Planning: a systemic approach" pp. 520-530 in Yiğitcanlar T. and Bulu M. (2013) eds 
Proceedings of the 6th Knowledge Cities World Summit, KCWS 2013, Lookus Scientific ISBN: 978-9944-380-11-9.

[3] Fistola, R., (2012), "Urban entropy vs sustainability: a new town planning perspective", pp. 185-204, in Pacetti M., Passerini G., Brebbia C. A., Latini G., The Sustainable City VII, WIT press, WIT Transactions on Ecology and The Environment, Vol. 155.

[4] Prigogine, I. \& Stengers, I., La Nouvelle Alliance, Gallimard, Paris, 1979.

[5] Pulselli M. R., Tiezzi E., Città fuori dal caos, Donzelli 2008, Roma.

[6] Aoki, I., (2012), Entropy Principle for the Development of Complex Biotic Systems: Organisms, Ecosystems, the Earth, Elsevier, London.

[7] Kaufmann, S. A., (1991), “Anthicaos and adaptation”, Scientific American, 265(2), August 1991.

[8] Fistola, R., "Ecourbanistica: toward a new sustainable town planning", in: Brebbia C., Hernandez S., Tiezzi E., (eds.), The Sustainable City VI. Urban regeneration and sustainability, WIT Transactions on Ecology and the Environment, Series Volume: 129. WIT Press 2010.

[9] Albeverio, S., Andrey, D., Giordano, P., Vancheri, A. (2008), The Dynamics of Complex Urban Systems. An Interdisciplinary Approach, PhysicaVerlag, Switzerland, 2008.

[10] Cabral, P., Augusto G., Tewolde M. and Araya Y. (2013) Entropy in Urban Systems, Entropy 15, No. 12: 5223-5236.

[11] Magee L., James P., Scerri A., 'Measuring Social Sustainability: A Community-Centred Approach', Applied Research in the Quality of Life, vol. 7, no. 3, 2012, pp. 239-61.

[12] Polése, M., \& Stren, R. (1999). The social sustainability of cities: Diversity and the management of change. Toronto: University of Toronto Press.

[13] Pope J., Annandale, D. \& Morrison-Saunders, A. (2004) Conceptualising sustainability assessment. Environmental Impact Assessment Review, 24.

[14] Mori K, \& Christodoulou A, Review of sustainability indices and indicators: Towards a new City Sustainability Index (CSI), Environ Impact Asses Rev (2011), doi: 10.1016/j.eiar.2011.06.001

[15] Finco A, \& Nijkamp P. Pathway to urban sustainability. J Environ Policy Plan 2001.

[16] Shen LY, Ochoa J., Shah M.N., Zhang X, (2010). The application of urban sustainability indicators. A comparison between various practices, Habitat International, Elsevier. 